\title{
Niñas en el sistema de justicia brasileño: El necesario debate sobre los derechos sexuales y reproductivos \\ (Girls in the Brazilian Justice System: The Necessary Debate on Sexual and Reproductive Rights)
}

OÑAT SOCIO-LEGAL SERIES VOLUME 10, ISSUE 2 (2020), 388-414: EL GÉNERO DE LOS SISTEMAS

PENALES JUVENILES: DEBATES NECESARIOS

DOI LINK: HTTPS://DOI.ORG/10.35295/OSLS.IISL/0000-0000-0000-1072

RECEIVED 05 FEBRUARY 2019, ACCEPTED 29 JULY 2019

\section{MARIA CRISTINA GONÇALVES VICENTIN* \\ DANIEL ADOLPHO DANTIN ASSIS*}

\section{Resumen}

En este artículo presentamos el debate brasileño sobre los derechos sexuales y reproductivos en su condición de derechos políticos que pueden favorecer avances significativos en la concepción y ampliación de los derechos de niñas, niños y adolescentes principalmente referidos al concepto de autonomía. A través de la revisión de los marcos legales y de la literatura, específicamente relacionados a las niñas en el sistema de justicia brasileño, evidenciamos tensiones entre el ejercicio de los derechos sexuales y reproductivos y las respectivas prácticas institucionales. Consideramos que es fundamental una perspectiva de protección que asegure las condiciones de integridad de sus cuerpos, pero que garantice simultáneamente el usufructo de los derechos relativos a la sexualidad. La articulación de derechos sexuales y reproductivos y la salud sexual y reproductiva puede ser un camino prometedor, especialmente para las adolescentes que encuentran mayores obstáculos para su ejercicio.

\section{Palabras clave}

Adolescentes mujeres; sistema de justicia juvenil; derechos sexuales y reproductivos; derechos de la infancia; autonomía

\footnotetext{
* Profesora asistente doctora, Departamento de Psicología Social de Pontifícia Universidade Católica de São Paulo. Datos de contacto: Pontifícia Universidade Católica de São Paulo. Rua Monte Alegre, 984, Perdizes São Paulo - SP CEP, 05014-901 (Brasil). Dirección de email: cristinavicentin@gmail.com

* Máster en derechos humanos, ciudadanía y políticas públicas de la Universidade Federal da Paraíba. Máster en Adolescente en conflicto con la ley. Datos de contacto: Rua Coronel Miguel Satyro, 30. João Pessoa-PB CEP 58045-110 (Brasil). Dirección de email: danieladolpho@gmail.com
} 


\section{Abstract}

In this article, we present the Brazilian debate on sexual and reproductive rights as political rights, which could bring significant advances in creating and broadening the rights of children and adolescents. By means of a revision of legal milestones and of the literature, more specifically that which relates to girls in the Brazilian justice system, we highlight tensions between sexual and reproductive rights and the respective institutional practices. We consider it crucial to have a protective perspective ensuring conditions for the integrity of their bodies, but that simultaneously guarantees the exercise of rights pertaining to body and sexuality. Coordinating sexual and reproductive rights and sexual and reproductive health may be a promising path, especially for those adolescents who find greater obstacles in exercising these.

\section{Key words}

Adolescent women; juvenile justice system; sexual and reproductive rights; childhood rights; autonomy 


\section{Índice/Table of contents}

1. Introducción 391

2. Derechos sexuales y reproductivos y salud sexual y reproductiva: marcos legales 396

3. Niñas en el sistema de justicia y acceso a los derechos sexuales y reproductivos.... 399

4. Derechos sexuales: ¿es posible conjugar autonomía y protección? 403

5. Consideraciones finales 407

Referencias 408

Referencias normativas 413 


\section{Introducción}

Este artículo se propone presentar el debate brasileño sobre los derechos sexuales y reproductivos como derechos que pueden favorecer avances significativos en la concepción y ampliación de los derechos de niñas, niños y adolescentes. Con el objetivo de aproximar el lector de las razones de esta elección, presentamos inicialmente dos situaciones que afectan los cuerpos de las niñas en las fronteras con el sistema de justicia brasileño. Estos ejemplos fueron elegidos porque se configuran como eventos críticos o analizadores en el sentido que les da el análisis institucional: permiten explicitar el juego de fuerzas actuando en una determinada situación, desmontando ciertas naturalizaciones (Lourau 1993) y apuntando modos alternativos de pensar-actuar.

Los casos Luiza y Fernanda, abajo narrados, eclosionan en Brasil ya en la vigencia de la nueva legislación ${ }^{1}$ para infancia y adolescencia y nos permiten demarcar algunas tensiones entre enfrentamiento y sumisión a los papeles tradicionales de género y de edad. Estas tensiones nos ayudan a situar los derechos sexuales y reproductivos y la salud sexual y reproductiva como un campo estratégico para pensar los derechos políticos de niños y adolescentes y la indisociabilidad entre autonomía y protección.

\section{Luiza $^{2}$}

El 21 de octubre de 2007, Luiza fue presa en Abaetetuba (en el Estado de Pará, región norte de Brasil), bajo la acusación de intentar robar un teléfono celular. Tenía 15 años, menos de 40 kilos y un metro y medio de altura. Llevada para la comisaría de la ciudad de 130 mil habitantes, a casi 100 kilómetros de Belém (capital del Estado), pasó los 26 días siguientes en una celda ocupada por más de 20 hombres. Durante todo el tiempo, fue estuprada incontables veces, tuvo cigarrillos apagados en su cuerpo y las plantas de los pies quemadas mientras trataba de dormir. Algunos detenidos, afligidos con las escenas repulsivas, apelaron a los carceleros para que interrumpieran el calvario. Los policías prefirieron cortar el cabello de la adolescente con un cuchillo para camuflar la apariencia femenina y mantenerla en la celda. El tormento sólo acabó con la intervención del Consejo Tutelar, ${ }^{3}$ alertado por una denuncia anónima. La actitud de la delegada que resolvió encerrar a Luiza no es sorprendente en los confines de Brasil. En el informe de la Comisión Parlamentaria de Investigación del Sistema Carcelario, publicado en 2009, comisarios, promotores, agentes penitenciarios y jueces confirmaron que "cuando no hay donde prender una mujer, la colocamos con los hombres". Hasta hoy el proceso contra los protagonistas de ese episodio corre en sigilo en el Tribunal de Justicia de Pará. En la denuncia, la promotora, mujer,

\footnotetext{
${ }^{1}$ La redemocratización del país en la década de 1980 y la promulgación, en 1988, de una nueva Constitución Federal introdujo en el ordenamiento brasileño una conciencia jurídica y social que reconoce niños y adolescentes como sujetos plenos de derechos, correspondiendo al Estado, a la familia y la sociedad, garantizar sus derechos con prioridad absoluta. Esta "nueva orden", fundamentada en la doctrina de la Protección Integral y consagrada por el Estatuto del Niño y del Adolescente (ECA; Ley nº. 8.069/90), rompe con la doctrina de la Situación Irregular, imbuida de un ideario de "protección" "asistencia" y "vigilancia" de esas personas, hasta entonces definidas como "menores" y objetos de la intervención jurídico-social del Estado, dentro de una óptica correccional-represiva que llevó a la institucionalización de una parte importante de niños y adolescentes pobres.

${ }^{2}$ Esta viñeta fue construida con base en dos reportajes, de los que extraemos fragmentos literales: Nunes 2016 y Bertolini 2016.

${ }^{3}$ El Consejo Tutelar es un "órgano autónomo, no-jurisdiccional, encargado de cuidar del cumplimiento de los derechos de los niños y adolescentes", conforme artículo 131 del Estatuto del Niño y del Adolescente (ECA; Ley $n^{\circ}$. 8.069/90).
} 
afirma que todos los agentes del estado sabían lo que pasaba y optaron por la omisión. Los únicos que siguen encarcelados son dos responsables de la violación que ya estaban detrás de las rejas cuando cometieron el crimen. Dos agentes de la prisión fueron exonerados en 2008. Uno cumple pena en régimen abierto. Los cinco comisarios fueron exonerados. La jueza, responsable de mantener a Luiza en la cárcel, fue jubilada compulsivamente por el Consejo Nacional de Justicia en 2010; dos años después, los ministros del Supremo Tribunal Federal (STF) anularon la decisión por considerarla "excesiva" y, en 2016, fue destituida por dos años de la magistratura por negligencia, ya que sólo solicitó la transferencia de la niña para una prisión adecuada "dos semanas después de recibir el oficio de la autoridad policial". Luiza estuvo bajo la protección del Programa de Protección a Niños y Adolescentes Amenazados de Muerte hasta completar 18 años. El 6 de junio de 2010, según la Justicia de la Infancia y la Juventud del Distrito Federal (Brasilia), emigró a otro programa destinado a adultos. Un reportaje de 2016 anuncia que, nueve años después del episodio, la joven lleva una vida desprotegida, de privaciones y miedo, a más de 3000 Km de Pará. A los 24 años, paró de estudiar, no tiene profesión fija, fue eliminada de programas de protección, convive con crack y teme ser muerta por traficantes, según relato de personas cercanas a ella. Desde mayo de 2011 el Estado paga una pensión mensual de dos salarios mínimos directamente a la joven a título de indemnización. ${ }^{4}$

\section{Fernanda ${ }^{5}$}

En 1996, el Supremo Tribunal Federal de Brasil juzgó un hábeas corpus impetrado por un hombre de 28 años, condenado a seis años de prisión por estupro de una niña de 12 años, en el municipio de Carmo de Minas (en el Estado de Minas Gerais), región sudeste del país. El ministro, relator del pedido de habeas corpus, votó por la absolución del hombre, alegando no sólo que la víctima, Fernanda, había consentido en la relación sexual, que aparentaba ser mayor de edad, que tenía vida sexual activa, como también que: "En los días de hoy, no hay más niñas, sino muchachas de doce años, precozmente maduras, la mayoría de ellas ya tienen suficiente discernimiento para reaccionar ante eventuales adversidades". El ministro también citó declaraciones de un testigo de defensa del reo, un hombre que calificó a la menor como "prostitucita", por haber mantenido relaciones sexuales con otros chicos. La posición y la declaración del ministro causaron perplejidad en gran parte de la sociedad brasileña, por abrir el camino a la impunidad de violadores de niños por medio de argumentos típicos del dominio masculino, que cuestionan el honor y la honestidad de las mujeres, tomadas todavía como objetos de uso y satisfacción de los hombres. La transformación de la víctima en rea y del reo en víctima es clara: si, por un lado, la menor es una "prostitucita", por otra, el plomero es casado y padre. La ley no podría asegurar la condena de un padre que fue seducido por una mujer que "cuenta, sólo, doce años" una vez que-de acuerdo con el ministro Marco Aurelio- "no se muestra inusual reparar la precocidad con que las chicas de hoy tratan, sin cualquier enredo, de asuntos concernientes a la sexualidad". Preguntado si su decisión no sería perjudicial para la lucha contra la explotación sexual de niños, el ministro respondió: "Cuando alguien dice eso, está cerrando los ojos a las causas de la prostitución infantil. Esta visión conservadora busca el castigo puro y simple de quien mantiene relaciones sexuales con menores. En realidad, lo que tenemos que investigar son las causas. Llegar a los problemas sociales". A la niña, sospechosa por pertenecer al género femenino, le quedan pocas opciones:

\footnotetext{
4 Todas las traducciones de textos y referencias en portugués son nuestras.

${ }^{5}$ Viñeta construida a partir de las siguientes referencias: Cruz Neto 1996, Silva y Silva 2007 y O Globo Brasil 2012.
} 
"hasta la policía piensa que fui yo quien forzó la situación. Dejé de estudiar y hasta tomé remedio para morir".

El caso Luiza evidencia de forma aguda como las relaciones de género y las de edad imponen relaciones de poder y jerarquizaciones que están más allá de aquellas "admitidas" por la ley. Desde el momento en que tal hecho fue publicitado, lo que emergió como reprensible del episodio era el hecho de que se trataba de una adolescente, haciendo suponer que la "simple" condición de mujer sujeta a tal orden de violaciones (en un país ratificador de las principales normas internacionales sobre tratamiento de reclusos y sobre la erradicación de la violencia de género ${ }^{6}$ estaría $^{2}$ naturalizada a punto de eximir responsabilidades.

Ese caso demuestra la complejidad de la consolidación de un campo de respeto a los derechos humanos en nuestro país y apunta, como sugiere Caldeira (2000), la persistencia de un cuerpo incircunscrito, desprovisto de los derechos individuales que lo resguarden, en el sentido de establecer barreras y límites a la interferencia o abuso de otros.

Luiza se ha convertido en un hito relativo a la violencia de Estado que afecta especialmente a las niñas en el sistema socioeducativo ${ }^{7}$ en Brasil $\mathrm{y}$, en cierto modo, delimitó una modificación del régimen de visibilidad de la condición femenina en los contextos de encarcelamiento y de su fase "generizada" (Baratta 1999). Por construcción "generizada" se entiende la incapacidad de proteger las demandas de mujeres y contemplar los agravios y las violencias contra ellas, observadas siempre por un lente moral que examina sus cuerpos y sus conductas y las victimiza doblemente: jurídica y moralmente (Brito 2007, p. 39).

De este acontecimiento crítico resultaron un conjunto de investigaciones (Ramos 2007, Fachinetto 2008, Arruda 2011, Conselho Nacional de Justiça 2015, Duarte 2016, Diniz 2017, Grillo 2018) sobre la situación de las adolescentes mujeres en el sistema socioeducativo brasileño que evidenciaron: la experiencia de vulnerabilidad vivida por las niñas antes de la llegada a la privación de libertad, vivenciada de forma diferente de la de los hombres; el cruce del sistema-género con otras formas de precarización de la vida -color, clase, territorio, educación- como determinantes de la entrada en el sistema socioeducativo; una distancia entre los marcos legales y las respuestas de las políticas sociales a las condiciones de vida de las adolescentes atendidas.

\footnotetext{
${ }^{6}$ Como evidencia también la violencia de género que caracteriza tan singularmente las relaciones sociales en el Brasil. El índice de homicidios contra mujeres en el período "entre 1980 y 2010 triplicó llegando a 230\%, o sea, en treinta años fueron asesinadas en el país más de 92 mil mujeres, 43,7\% en la última década" (Waiselfisz 2012, p. 08). En el año 2013, el Mapa de la violencia: Homicidios y juventud en Brasil, reveló que, en aquel año, más de 4.500 jóvenes del sexo femenino habían sido asesinadas en el territorio nacional. Entre 1980 y 2011 el número de víctimas llegó a 96.612, lo que representa un crecimiento de 233,5\%, siendo que casi la mitad (48.166) corresponde a la última década (Waiselfisz 2013, p. 74).

${ }^{7}$ La Constitución Federal previene, en su artículo 228, la inimputabilidad del individuo menor de 18 años de edad, o sea, caso practique una conducta considerada crimen o contravención (acto de infracción), deberá ser responsabilizado de acuerdo con lo previsto en el ECA y no de acuerdo con el Código Penal. Las seis medidas socioeducativas son: Advertencia, Obligación de Reparación de Daños, Prestación de servicios a la Comunidad, Libertad Asistida, Semilibertad e Internación. En relación a la práctica de delitos cometidos por chicos (con hasta 12 años de edad incompletos, art. 2º de la ECA) el Estatuto prevé la aplicación de medidas de protección (previstas en el art. 101) que no poseen el carácter de responsabilización.
} 
Ya el caso de Fernanda nos acerca al debate sobre las relaciones sexuales con menores de edad y apunta, en los juicios que involucran a niñas, por lo menos para dos situaciones: la condición de su cuerpo/sexo de mujer y del paradigma de la mujer "honesta/normal" (Brito 2007, p. 24) y a los márgenes de autonomía para el ejercicio de la sexualidad de los adolescentes. En este segundo episodio, vemos que se mezclan tensiones entre enfrentamiento y sumisión a los papeles tradicionales de género y conflictos relativos a los papeles de edad.

El avance normativo brasileño en el campo de los derechos humanos de niños y adolescentes sigue la nueva ordenación democrática constitucional de los años 1980 en adelante, que inspira legislaciones internacionales. A pesar de esto, enfrentamos dos obstáculos históricos para su efectivación: el nuevo texto legal no tuvo fuerza suficiente para aliviar las tensiones mencionadas frente a algunas leyes penales y civiles arcaicas que perduran. Inclusive con la reforma del Código Penal de 2009, las nuevas prescripciones normativas no son suficientes para producir nuevas estrategias de garantía de derechos.

De hecho, el Código Penal brasileño -desde la reforma introducida por la Ley Federal no 12.015- relaciona la capacidad de autodeterminación sexual a la edad de 14 años, invalidando el consentimiento para la práctica sexual. De este modo, se comprende que las relaciones sexuales con menores de 14 años son crímenes contra vulnerables, independientemente de la comprobación de discernimiento o no para el consentimiento de la víctima, o de cualquier otra circunstancia. Se trata de una protección objetiva frente al mayor riesgo de violación de derechos en comparación con otros rangos de edad.

Esa innovación redimensionó el lugar político de las personas con edad inferior a los 14 años, reconociéndolas, para efecto legal de exigibilidad de derechos, como vulnerables -independientemente de clase social, condición social, raza, etnicidad etc.

Pero otros juicios similares al del ministro del STF continuaron ocurriendo, incluso tras el cambio del Código Penal, bajo la alegación de que no se puede considerar delito el acto que no viola la libertad sexual. Del mismo modo se pronunció, en 2012, el Tribunal de Justicia sobre otra acusación de violación de menores de 14 años: "La prueba traída a los autos demuestra, muy bien, que las víctimas, en la época de los hechos, lamentablemente, ya estaban lejos de ser inocentes, ingenuas, inconscientes y desinformadas respecto al sexo. Aunque inmoral y reprobable la conducta practicada por el reo, no quedaron confirmados los tipos penales por los cuales fue denunciado" (O Globo Brasil 2012; subrayado nuestro). Y la relatora reafirma que

el derecho no es estático, debiendo, por lo tanto, amoldarse a los cambios sociales, ponderándolos, inclusive y principalmente, en el caso en debate, pues la educación sexual de los jóvenes ciertamente no es igual, teniendo en cuenta las diferencias sociales y culturales encontradas en un país de dimensiones continentales. (O Globo Brasil 2012)

Entendemos también que no es suficiente la salida adoptada por la vía legal de la reglamentación, como el caso de fijación de la edad de consentimiento para prácticas sexuales con adultos. De hecho, los debates legislativos en Suiza apuntaban, en los años 1980, cuánto una mera regulación de la edad de consentimiento para prácticas sexuales con adultos exponía a la responsabilización criminal también a los adolescentes que mantuvieran relaciones entre sí (Melo 2008). 
La situación vivida por Fernanda nos muestra que el debate sobre la libertad sexual de niños y adolescentes es parte de la dimensión objetiva de la autonomía y, por lo tanto, no puede ser hecho fuera de un campo relacional, bajo el riesgo de afirmar la indistinción niño-adulto. $\mathrm{O}$ sea, la ampliación de los derechos relacionados a la sexualidad de niños y adolescentes no puede fragilizar su inmunidad delante de las investidas adultas. Justamente lo contrario: el fortalecimiento del marco normativo de protección de la integridad y dignidad sexuales de los más jóvenes tiene también como objetivo distanciar, en tiempo y espacio, los comportamientos sexuales adultos, mientras continúen siendo comprendidos como no saludables al desenvolvimiento sexual de niños y adolescentes.

Menos aún se puede ubicar el debate fuera de un campo político, en la medida en que las relaciones de edad y de género son relaciones de poder. El caso Fernanda desvela el necesario debate sobre los derechos políticos de niños y adolescentes y, entre ellos, los derechos sexuales y reproductivos de la adolescencia, como parte de la necesidad de releerse la norma a la luz de los derechos de libertad.

De esta manera, es posible notar que las situaciones experimentadas por Luisa e Fernanda nos llevan al debate necesario sobre el ejercicio de los derechos relativos al cuerpo y a la sexualidad, en caso de niños/niñas y adolescentes, y evidencian tensiones en dos ámbitos de discusión: protección-violación/discriminación y protecciónautonomía. Obviamente, el caso Luiza expresa predominantemente el primer ámbito y el caso Fernanda, el segundo.

En un país con relaciones de poder extremadamente desiguales, es fundamental una perspectiva de protección que asegure las condiciones de circunscripción de los cuerpos. Por otro lado, en el caso de niños y adolescentes, más específicamente, su condición de "vulnerabilidad estructural" no puede impedir el ejercicio de los derechos relativos al cuerpo y a la sexualidad.

Como señalan Ribeiro y Busson (2008, p. 80), se trata de considerar que

si el sistema de género hace a las adolescentes más vulnerables, también tiende a condicionar sus voluntades, como no sujeto. Los derechos sexuales del niño y los derechos sexuales y reproductivos del adolescente son problemáticas que deben ser encaradas a través de un nuevo prisma, sin dejar de lado la protección que los niños y los adolescentes se merecen y tienen como garantía, por ser todavía vulnerables para la práctica de algunos actos de la vida civil, pero es necesario que los tabúes sean rotos, los prejuicios deshechos y que los derechos sean promovidos y garantizados, pues de derechos humanos se trata.

Consideramos, como otros colegas (Souza 2008, Melo 2008, Arantes 2009, Rosemberg y Mariano 2010), que la perspectiva de Protección Integral presupone una tensión, no una contradicción, entre protección y autonomía, entre sujeto de derechos y persona en desarrollo, entre prioridad absoluta y los demás intereses de la sociedad, reconociendo, sin embargo, la urgente necesidad de profundizar este debate, en la perspectiva de la integralidad e indivisibilidad de los Derechos Humanos, fortaleciendo las políticas públicas inclusivas y de calidad y valorizando la participación de niños y adolescentes.

En este artículo, por medio de la revisión de los marcos legales y de la literatura sobre derechos sexuales y reproductivos en Brasil, buscamos evidenciar las tensiones 
existentes entre estos derechos y las respectivas prácticas institucionales, teniendo como foco las niñas en el sistema de justicia.

Al evidenciar diferencias, en el campo de la sexualidad, entre derechos del niño y adolescente y derecho a la salud, se abre un campo táctico de articulación de derechos sexuales y reproductivos y salud sexual y reproductiva como un camino prometedor, especialmente para las adolescentes que encuentran mayores obstáculos para su ejercicio. Como veremos, tal vez resida allí una posible compatibilización de las protecciones, ya que el derecho a la salud remite a los -porque se realiza a partir de elloscampos de derechos de libertad (civiles y políticos) y de igualdad (sociales, económicos y culturales).

El artículo está organizado de la siguiente manera: inicialmente presentamos el debate brasileño y los marcos legales sobre los derechos sexuales y reproductivos; en seguida, trazamos las tensiones relativas al ejercicio de esos derechos en el campo de las prácticas institucionales con foco en las unidades de internación de niñas. Por fin, situamos el campo de los derechos sexuales y reproductivos y de la salud sexual y reproductiva como un campo estratégico para pensar derechos políticos de niños y adolescentes en la medida en que no disocian autonomía y protección.

\section{Derechos sexuales y reproductivos y salud sexual y reproductiva: marcos legales}

Los marcos regulatorios internacionales de los derechos sexuales y los derechos reproductivos (DSDR) de niños y adolescentes son, en Brasil, un campo de reflexión relativamente nuevo, sin dejar de ser innovador en el ámbito internacional. La institución, en 2012, del Sistema Nacional de Atención Socioeducativa (SINASE) como eje director de las políticas de ejecución de las medidas socioeducativas, presenta un nuevo campo de derechos sexuales y reproductivos cuya efectivación tiene impacto en el interior de las instituciones totales (Franco et al. 2012). Por otro lado, el contexto relativo a la salud también se destaca al reconocer, en la letra de la ley, un cúmulo de derechos de acceso y permanencia a los servicios sin desconsiderar la autonomía. Mientras tanto, retomemos, brevemente, el marco internacional que, en diálogo con el pionerismo brasileño, culminó en el tejido legal que tenemos actualmente acerca de los DSDR.

En el ámbito de la Organización de las Naciones Unidas, hubo diez Conferencias pertinentes, iniciadas por la de Roma (en 1954). Los temas estructurantes se orientaban sobre la relación entre población y desarrollo, derechos humanos y control demográfico, hasta que en las tres últimas, se rompe con el paradigma que reducía la temática a la fecundidad, bajo el manto del crecimiento vegetativo. Firmante de las principales normas supranacionales sobre el tema, Brasil se inclinó especialmente sobre la Conferencia Internacional de Población y Desarrollo (El Cairo, Egipto, en 1994), la IV Conferencia Mundial sobre la Mujer (Beijing, China, en 1995) y los encuentros de El Cairo+5 (descentralizados, participando Brasil del celebrado en Santiago, Chile), organizados por las Naciones Unidas.

En la Conferencia de El Cairo se daba la largada para la emancipación de las mujeres acerca de uno de los temas más intangibles: la inclusión de la dimensión sexual y su desplazamiento hacia el ámbito de las libertades civiles, contando con el liderazgo de 
Brasil, que en esa perspectiva se conducía internamente desde 1983, cuando se instituyó el Programa de Asistencia Integral a la Salud de la Mujer (PAISM). Aunque los pasos inaugurales de este programa y otras acciones realizadas entre las décadas de 1980 y 1990 colocaron al país en posición de destaque internacional, el Monitoreo de El Cairo informa que Brasil no implementó diversas directrices aclamadas en 1994 y conferidas y ratificadas cinco años después. Entre varios motivos identificados, se constató que el hecho de que el país ya estaba avanzado hasta la primera Conferencia de El Cairo, le reservó cierta negligencia en mantener la misma celeridad para los demás pasos, haciéndole caer gradualmente de la posición hegemónica en el mundo (Oliveira 2004).

El Cairo+5 apunta a avances significativos en el campo de los agravios a la salud derivados de las prácticas sexuales y reproductivas (por ejemplo, VIH, sífilis y hepatitis B), y menos de la producción de sentidos éticos de autonomía de niños y adolescentes. En la adolescencia ganan centralidad las estrategias de prevención de las inmunodeficiencias y enfermedades infecciosas, siendo el enfrentamiento al VIH una de las divisas que aún sitúan a Brasil como referencia internacional. En este contexto, inspirado en la agenda paralela del enfrentamiento a las diversas formas de violencia sexual contra niños y adolescentes, en 2000, Brasil edita el primer Plan Nacional de Enfrentamiento de la Violencia Sexual contra Niños y Adolescentes, haciendo que el tema gane espacio incluso en los medios de comunicación de masa, con un alcance arrebatador en la sociedad brasileña a lo largo de esas dos décadas que terminan. Con eso, se vuelven las luces al país, que llega a albergar el III Congreso Mundial de Enfrentamiento de la Explotación Sexual de Niños y Adolescentes. Aparentemente, en Brasil, la perspectiva del daño y de la violación sigue siendo la tónica que más prospera y gana más espacio en debates y construcción de políticas públicas que la lógica del derecho, que parece no tener fuerza suficiente y constante en la agenda institucional nacional. Veamos.

Frente al escenario de doble prisma (de los lentos avances en la perspectiva de la autonomía y de las rápidas conquistas sobre la protección estatal ante la violencia y los agravios a la salud), muchas normas internas fueron editadas por el Ministerio de Salud y Ministerio de Educación, convergiendo, por ejemplo, con el Programa Salud en la Escuela (Decreto no . 6.286). Sin embargo, a la luz del Estatuto del Niño y del Adolescente, tales normas aún refuerzan el evidente desequilibrio entre protección y autonomía, como si esas dimensiones juntas no pudieran caminar.

En el contexto socioeducativo cerrado, surgen nuevas estrategias de afirmación de derechos y producción de cuidado en las experiencias marginales de la institución total $\mathrm{y}$ en las relaciones entre adolescentes para su resistencia y supervivencia.

En este sentido, en 2008, el Ministerio de Salud (Portaria Interministerial $n^{\circ}$. 647) oficializó el debate dentro de las unidades de internación: bajo el título Salud Sexual y Salud Reproductiva, inauguró el tema, aunque en atraso con el debate en libertad. Sin embargo, nuevamente trae limitaciones en relación al horizonte normativo que se quiere alcanzar: restringe las acciones coordinadas al contexto de las mujeres cisgénero y las atrinchera en la dimensión orgánica (de la sexualidad, de la reproducción y de la lactancia materna). Sólo con el advenimiento del SINASE se abren nuevas puertas para la evolución del debate en las perspectivas de la autonomía y la no violación. 
El SINASE articula los entes federativos y sus diversos órganos (de educación, salud, seguridad, asistencia social etc.) para el desarrollo de los programas de atención socioeducativa, considerando la intersectorialidad y la corresponsabilidad de la familia, la comunidad y el Estado, definiendo las atribuciones de los diversos actores en la financiación, ejecución, fiscalización y evaluación del sistema, así como trazando directrices pedagógicas que reafirman la naturaleza preponderantemente educativa de las medidas (priorizando aquellas ejecutadas en medio abierto en detrimento de las restrictivas de libertad) (Ley $\mathrm{n}^{\circ}$. 12.594).

Esta ley es vista como la primera para la ejecución de Medida Socioeducativa (MSE) en el país (Ley no. 12.594), siendo evaluada por defensores/as de los derechos humanos como un avance importante en la garantía de los derechos de los adolescentes y jóvenes en la medida en que crea parámetros para su garantía y reconocimiento por el Estado, por medio de políticas públicas que aseguran acciones, programas, servicios y otros dispositivos para efectuar los derechos fundamentales (Frasseto et al. 2012, Jimenez y Frasseto 2015). ${ }^{8}$

Sin embargo, la implementación del SINASE todavía está lejos de ser asegurada en lo que se refiere a los derechos de libertad. Depende del reconocimiento de las corresponsabilidades de los diferentes actores gubernamentales y de la comprensión de la lógica de organización entre los sectores involucrados para la consolidación del principio de la incompletud institucional y de los ejes primordiales de garantía de derechos de adolescentes y jóvenes en Brasil (Perminio et al. 2018).

Sin embargo, en relación a los DSDR, el SINASE avanza sobre temáticas no contempladas en el Estatuto del Niño y del Adolescente (ECA) que privilegia una lectura "negativa" de la sexualidad (más como protección a las violencias sexuales). Su innovación se da en el ámbito de los derechos de libertad, como garantía de los derechos sexuales y los derechos reproductivos de esas adolescentes y jóvenes. Desde el SINASE se incluyen el derecho a la visita íntima, cuando están casadas o viviendo en unión estable y el derecho a la libre expresión de sus orientaciones sexuales, así como los relacionados a la contracepción, a la prevención de enfermedades de transmisión sexual, de hepatitis virales y de infecciones por el virus de la inmunodeficiencia humana (VIH), a la atención a la salud en los procesos de embarazo, aborto, prenatal, parto y puerperio, y a la lactancia materna de sus hijas e hijos.

Por un lado, el SINASE aborda los DSDR de modo tímido cuando reitera algunos dispositivos legales preexistentes en el Estatuto del Niño y del Adolescente, pero innova a través de normas que modulan los modos de ejercer esos derechos. Por otro lado, se trata justamente de derechos que componen con los DSDR la dimensión de libertad (autonomía) al garantizar en el Sistema Nacional el derecho a la información, educación,

\footnotetext{
8 El SINASE constituye un complejo documento de propuestas y afirmaciones que reorientan, por primera vez en el país, el modelo de ejecución de medidas socioeducativas, delegado hasta ese momento a los órganos judiciales estaduales. Su llegada impactó positivamente el contexto de promoción, defensa y control de la efectivación de los derechos humanos de adolescentes en conflicto con la ley al establecer patrones de conducta del Estado e inscribir en la legislación derechos que deben ser garantizados también en el interior del sistema. Cabe señalar, sin embargo, que SINASE opera paradójicamente produciendo por un lado la inclusión del adolescente como un objeto de gobierno y, por otro lado, la exclusión, en la medida en que no garantiza la condición de sujeto de los derechos.
} 
adquisición de competencias y demás medios y métodos para que las personas tomen decisiones sobre su vida sexual y reproductiva; el derecho a la igualdad, a no ser discriminado y a la diferencia; y el derecho a la privacidad y a la intimidad.

En otras palabras, la institución de un nuevo modelo de atención a la salud sexual de adolescentes ocupó más recientemente en nuestro país diferentes espacios de discusión en la búsqueda de reconocimiento de la autodeterminación en el ejercicio de la sexualidad y de la capacidad reproductiva como una dimensión de la salud. Se trata de una dupla configuración de los DSDR: derecho a la salud en la perspectiva de la autonomía y derecho de libertad en la perspectiva de la salud.

De hecho, en la perspectiva de la salud y la educación, se buscó establecer políticas y acciones públicas que aborden la temática de la educación sexual y amplíen el acceso a la atención integral a la salud sexual y reproductiva del adolescente. La perspectiva es que niños y adolescentes construyan autonomía y desarrollen habilidades en las cuestiones relativas a la sexualidad, que favorezcan tanto la toma de decisiones frente a las violaciones de derechos como la vivencia de su sexualidad en el cotidiano (Ventura 2009, Oliveira 2011). Para ello, es necesario reequilibrar la balanza de los derechos sexuales y los reproductivos, dado que, en Brasil, estos últimos fueron más fortalecidos que aquellos. Más que eso, según afirma el propio Ministerio de Salud, los derechos sexuales nao deben restringirse al campo de la salud, sino ser contemplados en una dimensión más amplia de derechos humanos (Ministério da Saúde 2010).

\section{Niñas en el sistema de justicia y acceso a los derechos sexuales y reproductivos}

Una visión para las prácticas institucionales nos mostrará la distancia entre los marcos legales aquí presentados y su efectivación en, por lo menos dos sentidos: en cuanto a la atención a la diversidad de género y en cuanto al ejercicio de las adolescentes de sus derechos sexuales y reproductivos. Así lo apuntan diferentes investigaciones del contexto socioeducativo, en especial la publicada por el Consejo Nacional de Justicia, según la cual "parece que la misma lógica patriarcal se reproduce en el ámbito de las adolescentes de sexo femenino, especialmente al no observarse cuestiones específicas relativas a la sexualidad", donde "ser mujer en el sistema socioeducativo o penal es ser invisible" (Conselho Nacional de Justiça 2015, p. 10). Tal pesquisa indicó además que todos los estados investigados en la ejecución de las medidas socioeducativas de internación, realizan algún grado de violación a los derechos humanos de las niñas, desde las deficitarias estructuras físicas hasta la ausencia de visita íntima, pasando por serios problemas referentes a la escolarización, a la disciplina interna de la unidad, la higiene, salud y maternidad y que, además de no corresponder a mínimas exigencias de protección integral, no están preparadas para enfrentar las cuestiones de género que circundan a las adolescentes.

En estas instituciones se verifican la valorización de patrones y comportamientos afinados a modelos de conducta socialmente aceptados y reconocidos como del sexo femenino, como la pasividad y la obediencia. Así, no fue inusual encontrar, como apunta la investigación del CNJ, "en todas las unidades visitadas, las adolescentes corresponsables por la realización de las tareas de limpieza, alimentación y otras que 
ordinariamente son consideradas como domésticas" (Conselho Nacional de Justiça 2015, p. 190).

En el sistema socioeducativo, las formas de administrar y relacionarse con las niñas (y también con los niños) son generalmente oriundos de la cultura policial masculina (Arruda 2011, Diniz 2017, Grillo 2018). Comúnmente, en las conversaciones de los funcionarios, las niñas son consideradas como más difíciles de trabajar por la "supuesta irracionalidad" con que se presentan, "por su mayor impulsividad y emotividad" (Conselho Nacional de Justiça 2015, Diniz 2017).

La manera como las adolescentes operan en estos espacios es entendida como de emociones extremas, agresividad, convirtiéndose tales interpretaciones en sinónimo de falta de respeto a los funcionarios, cuando podrían ser comprendidas como tácticas de resistencias femeninas al contexto opresor que experimentan (Grillo 2018). El movimiento, las insubordinaciones y tensiones que las niñas ejercen con sus cuerpos en los espacios de privación de libertad, se convierten en enfrentamientos al orden vigente, son resistencias a los rituales de procedimientos tan presentes en estas instituciones. Diniz (2015) dice que la "indisciplina se caracteriza por un gesto central de formación del cuerpo" de las niñas en los reformatorios: "ellas se resisten a los rituales de procedimiento". Mientras los niños caminan mirando hacia el suelo, ellas ponen en escena la insubordinación, que es una "ambigüedad en la performance del sexo como un monumento del género" (Diniz 2015, p. 237).

Esta actitud de insubordinación evidencia modos singulares de resistencia (particularmente si se compara a las formas de resistencia de los niños) pero no puede ser separada de la condición incircunscripta de los cuerpos y del esfuerzo cotidiano de las niñas de hacer frente a los asedios y violaciones realizadas por funcionarios, situaciones estas que ni siquiera ganan condiciones de denuncia o de visibilidad.

Más específicamente en relación con los derechos sexuales y reproductivos, cabe destacar que, en ninguna de las unidades visitadas en la investigación del Consejo Nacional de Justicia, "las adolescentes estaban autorizadas a recibir una visita íntima. Sin embargo, muchas de ellas poseían compañeros/as, novios/as, a veces ya vivían con ellos o tenían hijos, representando una violación al derecho a la sexualidad" (Conselho Nacional de Justiça 2015, p. 210). Y, como señala Arruda (2011, p. 204), “como las relaciones entre las niñas no tienen estatus de acto sexual, las cuestiones pertinentes a la salud sexual se colocan debajo de la alfombra, como si no existieran".

Así y también por un uso recurrente de normas, contención y disciplinas que tienden a reforzar un modelo de atención pautado en la discrecionalidad, son encontradas otras situaciones de falta de respeto al ejercicio de la sexualidad como "las referencias a la 'libido exacerbada' en los informes de evaluación de la medida; el 'beso dado' que lleva a la sanción-reflexión; la medicalización como estrategia de control y normalización de los cuerpos; y las relaciones lésbicas consideradas como 'resultado de carencia y soledad', 'transitorias' y 'limitadas a la realidad institucional' e ignoradas como ejercicio de sexualidad" (Arruda 2011, p. 212). En consecuencia, estas relaciones tampoco se abordan en términos de políticas de salud, prevención de enfermedades de transmisión sexual, en la vida diaria de las unidades. 
Además, aunque la relación homoafectiva aparezca frecuentemente en las unidades, como, en distinto grado, la transgeneración, ambas son pasibles de sanciones creadas y aplicadas a criterio de cada Unidad. Es importante recordar que recaen sobre los/las adolescentes homosexuales, bisexuales y transexuales el prejuicio y un mayor control, arraigados en el discurso médico-patológico y también en el de profesionales que ven en la orientación sexual o en la identidad de género, un desvío de conducta en virtud del contexto vivido. Las situaciones de abuso, por ejemplo, se mencionan todavía como una de las "causas" para tal "comportamiento desviado".

Los paradigmas institucionales de los programas de atención giran en torno a la búsqueda por la mejora del comportamiento individual de la infractora, por la resocialización y la reeducación de las niñas para la vida en sociedad, con el apoyo de su familia. En una matriz patriarcal, la responsabilidad de las jóvenes por el éxito de sus vidas está en gran medida aliada a sus vínculos generacionales y relaciones interpersonales, encontrándose con frecuencia en las orientaciones socioeducativas la sugerencia/necesidad de alejamiento de las jóvenes de sus novios o amigas, a quienes se atribuye participación en la infracción (Froemming 2016).

También destacamos que las prácticas institucionales contrarias a la propia legislación, como lo demuestran los casos de Luiza y Fernanda, entienden que la falta de estructura familiar de la que proceden estas niñas se atribuye a menudo a la ausencia de la figura paterna o a la mala gestión materna de la familia (Caetano et al. 2019). En ambos casos, percibimos la prevalencia de la lógica patriarcal, ya que la figura paterna podría haber sido una respuesta redentora a la vida de estas jóvenes mujeres, mientras que la figura materna demostró ser ineficaz.

Por un lado, es pertinente la hipótesis de Diniz (2015) de que algunas de las niñas que ingresan al sistema socioeducativo no son "las fuera de la ley del género", como las prostitutas o las mujeres independientes (esta es la hipótesis que movió los estudios históricos sobre los sentidos de la prisión o de los asilos para el encarcelamiento de las mujeres), sino las que están capturadas por el orden del género, siendo subordinadas "al poder de los hombres o al orden familiar por la pasión, el sexo o la dependencia". Pero, por otro lado, Duarte (2016) señala que las adolescentes vienen rompiendo con el silencio de la violencia de género, aunque sea al cometer el acto infractor.

Transforman en visibles sus demandas, y con eso hacen de un asunto históricamente tratado en privado, una demanda pública. Si antes la privación de libertad para adolescentes se basaba en el ámbito del hogar, las transformaciones en la dinámica social que afectaron al mundo del trabajo, sumadas a las nuevas exigencias y sobrecargas de las mujeres, traen implicaciones a la dinámica institucional. Hasta recientemente intentos de reproducir en la unidad los estereotipos socialmente construidos de género eran más "eficaces" que hoy. Aunque es una vertiente afirmada en el sistema, el mantenimiento del estereotipo pensado a partir de una idealización femenina, reproductora, heterosexual está siendo cada vez más cuestionado. Son los/las propios/as adolescentes quienes resisten con sus cuerpos, identidades y orientaciones a la norma impuesta (Duarte 2016, p. 143). En alguna medida, ellas tratan de ejercer sus derechos de libertad por medio de prácticas de resistencia en afirmación del derecho al desarrollo sexual saludable y del derecho a la autonomía de género. 
En la misma dirección, Ramos (2007) considera que la construcción social de la vulnerabilidad penal de las niñas privadas de libertad pasa por trayectorias de vida marcadas por acciones de enfrentamiento a los papeles tradicionales de género, inicialmente en el espacio privado y luego llegando al espacio público (escuela, programas protegidos, comunidad), como vimos confirmarse en las diferentes investigaciones de las trayectorias que anteceden a la entrada de adolescentes en el sistema de justicia.

Finalmente, es necesario subrayar que la realidad punitiva de esas organizaciones tiene efectos inmediatos en niñas integralmente dependientes del Estado en relación a disponer de alternativas de proyectos de vida después de la internación: el proceso socioeducativo además de no haber permitido el desarrollo de nuevos proyectos de vida se ha convertido, como indican Diniz y Paiva (2014), en un atajo para el itinerario punitivo en la vida adulta. ${ }^{9}$

Así, contrariamente al marco legal existente, adolescentes y jóvenes del sexo femenino en situación de internación provisional o cumpliendo medida socioeducativa están lejos de tener estos derechos asegurados. Como señalan Franco, Racy y Simonetti (2012), a pesar de estar en la pauta de los debates de las Ciencias Sociales y de la Salud Colectiva, el tema de los derechos sexuales y reproductivos de mujeres adolescentes-jóvenes internadas en unidades socioeducativas todavía continúa siendo poco desarrollado en la doctrina jurídica. ${ }^{10}$

La visibilidad creciente de la violencia contra la mujer, de la homofobia, la mortalidad y la morbilidad por aborto inseguro, la expansión del VIH entre las mujeres adolescentes encuentran ciertamente respuestas consecuentes por el acceso a la dimensión de la salud sexual y reproductiva como derecho a la salud, pero son respuestas insuficientes si no las relacionamos al campo más amplio de factores sociales, culturales, políticos y económicos que producen tales situaciones, entre ellos el no reconocimiento y la violación de los derechos sexuales y derechos reproductivos.

Así, si hay un camino provechoso de interferencia de las acciones de la salud en el campo socioeducativo, será importante, aún, no reducir una dimensión a la otra, para no excluir

\footnotetext{
${ }_{9}$ Débora Diniz y Juliana Paiva (2014) señalan, a partir de una investigación recientemente realizada en el Distrito Federal (Brasilia), que una de cada cuatro mujeres sentenciadas en régimen cerrado pasó por medida socioeducativa de internación en la adolescencia con un itinerario marcado por: violencia doméstica, vida en la calle, uso de drogas.

10 A principios del año 2019, se propuso la Resolución que establece directrices para la atención socioeducativa a las adolescentes privadas de libertad en el Sistema Nacional de Atención Socioeducativa (SINASE) (Ministério da Mulher, da Família e dos Direitos Humanos 2019; hasta el momento de la finalización de este artículo, no se ha realizado la implementación de la Resolución). La propuesta atiende a la garantía de los derechos sexuales y reproductivos, así como las que pretenden crear condiciones institucionales para que se eviten apremios y violaciones como: el vedamiento a los agentes socioeducativos hombres en la ejecución de rutinas internas regulares; las medidas que prohíben la exposición de la intimidad de las adolescentes en las unidades; las medidas que "prohíben cualquier procedimiento disciplinario" u otras formas de castigo, independiente de la orientación sexual o de género, en sus expresiones de afecto y prohibición de prácticas que imposibilitan la libertad de expresión de género de las adolescentes. Por último, se debe dar destaque a la exclusión de la medida de internación en relación a las adolescentes gestantes, lactantes, madres y titulares de guardia o tutela de niños y adolescentes y a la garantía a informaciones sobre formas de contracepción y prevención de infecciones de transmisión sexual incluyendo el acceso y orientación sobre el uso de preservativos.
} 
del campo de debates los demás territorios políticos, como aquel en que se encontraba Fernanda. En este sentido, es necesario mirar las tensiones que se plantean entre protección y autonomía.

\section{Derechos sexuales: ¿es posible conjugar autonomía y protección?}

Diferentes estudiosos señalaron que, a pesar de la construcción del niño como sujeto de derechos, los fundamentos políticos y jurídicos que influenciaron esa mutación enfocan todavía más en la garantía del derecho de protección y cuidado que en la legitimación de la sensibilidad y perspectiva del niño en sus singulares relaciones con los adultos. Los estudiosos sugieren que es necesario reflexionar sobre las consecuencias de esta actitud proteccionista en términos políticos, en la medida en que ese discurso fomenta una condición de incapacidad sociopolítica del niño y de los adolescentes (Castro 2001, Souza 2008). Fajardo (2003) destaca que esta asimetría se ve reforzada por la "ideología de la incapacidad" infantil, que se utiliza del concepto de discernimiento asociado a la edad, como un criterio para la restricción de derechos.

De hecho, con el acento en la lógica del daño y de la violación, los nuevos derechos del niño en nuestro país, se utilizarán más en su faceta protectora para combatir la doctrina de la "situación irregular" que orientaba el Código de Menores de 1979 (Rosemberg y Mariano 2010, p. 716), dando poco lugar a los derechos de libertad, a los derechos políticos o, también, a los derechos de participación bien como al reconocimiento de la capacidad de niños y adolescentes de elegir, garantías típicamente localizadas en la lógica autonomista. Cuando tenemos una protección disociada de autonomía, sería mejor hablar de una "protección tutelar" (Souza 2017), que mira la protección solamente como la no violación del derecho, diferente del actual sistema garantista, que trata de imponerse a partir de la afirmación de la autonomía y capacidad relacional.

A pesar del marco legal brasileño estar de acuerdo con las directrices y recomendaciones internacionales y legislaciones más avanzadas sobre el tema, la concepción del niño y del adolescente como sujetos portadores de derechos propios, autónomos y libres "no está enteramente comprendida o aceptada por la cultura, produciendo controversias políticas y legales que, en los últimos años, se han convertido en blanco de ataques sistemáticos del conservadurismo moral" (Ventura y Corrêa 2006, p. 1506). Tal es el caso de los derechos sexuales y reproductivos que aún hoy son ignorados, "revelando la persistencia de patrones moralistas y la idea de prohibición e interdicción de la vida sexual y reproductiva" (Pirotta y Pirotta 2005, p. 88).

Por su parte, el derecho brasileño considera la garantía del derecho a la sexualidad de niños y adolescentes sólo por el sesgo represivo, volcado a la responsabilización de los agresores. Es lo que muchas veces se expresa en voces de defensa de adolescentes como Fernanda: punir el agresor se comprende como conquista concreta e inmediata. Es decir, se habla del "enfrentamiento de la violencia sexual contra niños y adolescentes" y no de la afirmación y de la "garantía de sus derechos sexuales y reproductivos" como ya se pretende reconocer en el área de la salud, sin pleno consenso en el mundo jurídico. Esa falta de una explícita mención en la legislación genera dudas, en especial relacionadas al derecho de acceso a las informaciones, a la educación sexual y a los servicios de salud sexual y reproductiva para los adolescentes. Una de las dudas más persistentes es en 
cuanto a la necesaria anuencia de los padres o responsables en relación al acceso a los derechos (Ventura y Correa 2006, Ventura 2009).

Cuando se oculta información a los adolescentes o cuando se dificulta el acceso a los servicios de salud reproductiva, se les niega la oportunidad de tomar decisiones conscientes y adecuadas a su cotidiano y en cierto modo se les impide ejercer su sexualidad de forma sana y responsable.

A pesar de la hegemonía de las posiciones institucionales más próximas de la protección tutelar, la perspectiva de la autonomía emerge en otras situaciones que abren flanco de resistencia y, más, afirmación. Ya en 2008, el Manual de Orientación de Salud del Adolescente de la Federación Brasileña de Ginecología y Obstetricia -FEBRASGO (2008)- hizo las siguientes recomendaciones para el atendimiento de adolescentes en la red de salud:

- La ausencia de los padres o responsables no debe impedir las acciones de atención a la salud de los adolescentes.

- Los padres y los responsables sólo serán informados sobre el contenido de las consultas con el expreso consentimiento del adolescente.

- En situaciones más complejas, se recomienda que el equipo de salud encoraje el adolescente a buscar la implicación de su familia. Sin embargo, los límites deben estar claros: el joven debe ser incentivado a implicar la familia, pero la decisión final es de él (FEBRASGO 2008, p. 56).

Otra posición afirmativa, originada en el campo de la salud sexual, problematiza la recurrente concepción de sexualidad de los adolescentes (supuestamente más próxima de la experiencia adulta) como una práctica negativa y "prematura", adjetivo comúnmente empleado en los casos de embarazo de adolescentes. Diferentes investigaciones que analizan los sentidos atribuidos al embarazo de adolescentes apuntan para la posibilidad de ser una decisión de las jóvenes: sea como resultado de su inserción en un ambiente que, de cierto modo, limita sus proyectos de escolaridad y calificación profesional; sea como una garantía de conquista de status social frente a las dificultades de esas jóvenes inserirse como mujeres en otros espacios valorizados por la sociedad; o, también, por un posicionamiento objetivo del deseo de ser madre. (Carvalho et al. 2012).

La falta de reconocimiento de derechos sexuales a niños y adolescentes implica una violación al principio de no discriminación (Melo 2011). Aunque se hable internacionalmente de estos derechos, las edades de consentimiento se han establecido arbitrariamente, con gran variedad y por debajo de las cuales estos derechos no tienen expresión (Melo 2018). El mismo autor llama la atención sobre la posición crítica del Child Rights International Network (CRIN) concerniente a la fijación de las edades mínimas de los niños (para que se transformen en sujetos a las mismas leyes previstas para los adultos o puedan ser considerados como teniendo capacidad de toma de decisiones y de juicio), admitiendo que "estas restricciones desconsideran circunstancias individuales del niño y en algunos casos pueden reducir su protección, como, por ejemplo, para hacer una queja o buscar un asesoramiento sin consentimiento parental" (Melo 2018, p. 171). Así, tal como se manifestó la FEBRASGO, el CRIN postula que todos los niños deberían tener acceso a servicios de salud sexual y reproductiva, 
independientemente de su edad, debiendo suponerse que todo niño que busca tales servicios es capaz y que el acceso se hará en su interés superior (ver Child Rights International Network 2016).

No se trata de ignorar las violencias cometidas por las familias y el Estado contra niños, pero tampoco se puede dejar de ejercitar la crítica en cuanto a la perpetuación de la estructura familiar (especialmente el patriarcado) y en cuanto a las intervenciones preconcebidas de las políticas en el ámbito de las vidas de niños y adolescentes de forma universal y sin consideración de singularidades individuales, familiares y sociales.

Como señala Ventura (2009), este tipo de tratamiento denominado negativo es, sin duda, necesario para prevenir abusos sexuales, pero lo que se critica es la acogida de esta única perspectiva en el ordenamiento jurídico brasileño una vez que el modelo exclusivamente penal-punitivo para el tratamiento de aspectos que afectan a la intimidad de las personas ha sido insuficiente e ineficiente para prevenir y cohibir prácticas abusivas.

Además este endurecimiento legal, principalmente el que se estructura alrededor de la idea de consentimiento, en nombre de la protección, "apaga dimensiones existenciales, imposibilita encuentros -amorosos, experimentales, afectivos, placenteros- entre adolescentes, con los placeres, así como la digresión en relación con patrones y reglas" (Melo 2018, p. 176).

Sabemos que "los derechos sólo pueden ser efectivos si son constituyentes de una estrategia de transformación social, articulados con sentidos comunes y con prácticas sociales" (Freeman 1997, p. 16). La construcción del campo formal de derechos del niño y del adolescente como sujetos de derechos es importante pero insuficiente para pensar la inserción de niños y adolescentes en la comunidad política. Mucho menos debe ser entendido como un momento pleno de los vínculos sociales entre niños y adultos. Pensamos que son especialmente los momentos instituyentes creados en la relación con los niños y adolescentes que pueden configurar el campo de su posición política, cuando los vínculos de la infancia y la adolescencia hacia la sociedad más amplia pueden ser resignificados y redefinidos, cuando estos descentran la sociedad e interrogan el lugar de la discursividad política hegemónica, introduciendo transformaciones (Castro 2007).

Según Melo (2008, p. 44), es necesario comprender cuanto el cambio de paradigmas no puede darse sin una profundización sobre las varias dimensiones normativas que dictan el control de la sexualidad y su carácter eminentemente político. Sin un énfasis en la reflexión sobre el lugar social de niños y adolescentes y las discriminaciones de edad y de generaciones a las que están expuestos, no se podrá reconocer efectivamente sus competencias y su derecho a la participación y al ejercicio de sus derechos. Pretender hablar de nuevos derechos en el campo de la sexualidad y de una justicia orientada a la emancipación de los sujetos no será posible en el campo de los derechos humanos sin una revisión de conceptos como protección y desarrollo, de norma y derecho y sobre todo, de protagonismo social de niños y adolescentes.

Como apunta Souza (2008, p. 97), uno de los desafíos actuales es

... ecuacionar la tensión que se instala entre conceder mayor autonomía a la infancia y a la adolescencia, derecho de voz y de participación política, con miras al alcance de lo que definimos como meta para alcanzar la excelencia humana y el riesgo de que esta práctica pueda favorecer una cierta omisión de los adultos y las instituciones, en 
construir, junto con los niños y adolescentes metas que garanticen la protección de sus derechos en un contexto de definiciones claras y en relación con el bien humano.

Entonces es necesario restituir una mayor precisión a la noción de autonomía como ampliación de las redes de interdependencia, no en una perspectiva neoliberal o individualista -que subyace a los discursos del protagonismo juvenil- y que se orienta por la retirada de responsabilidad del Estado y de la sociedad en la misma medida de la ampliación de la responsabilidad del joven. Para tanto, recorramos a otro contexto de defensa de derechos humanos.

El campo de lucha de las personas con discapacidad atravesó contextos similares a los de la infancia y adolescencia en su búsqueda por emancipación y los llevó a problematizar nociones como discernimiento, capacidad y autonomía. De ese escenario podemos extraer algunas novedades que nos ayudan a producir prácticas institucionales de protección con autonomía para el campo de la infancia y adolescencia, aproximando los marcos legales de la efectivación de los derechos humanos de ese segmento. Al comprometer el Estado para el cumplimiento de deberes para garantir igualdad de condiciones de las personas con discapacidad con las demás personas, la Convención sobre los Derechos de la Persona con Discapacidad (Organización de Naciones Unidas 2006) innova al elevar al titular de sus derechos de un grado de baja contractualidad social para el nivel de horizontalidad social.

Se trata de un paradigma de reconocimiento de que la incapacidad era una construcción sociopolítica de carácter autoritario, en la medida en que se realizaban dos reducciones: la persona siempre fue reducida a su discapacidad; la discapacidad siempre fue reducida apenas a atributos intrínsecos de la persona.

Está vigente actualmente la perspectiva según la cual se trata de deshabilidad, comprendida como apenas una de las dimensiones de la vida y constituida por discapacidades que se concretizan en la medida en que interactúan, forzosamente, con barreras actitudinales, sociales, arquitectónicas, etc. La Convención expresa el establecimiento de la capacidad legal de todas las personas con discapacidad para ejercer los mismos derechos y en igualdad de condiciones (generadas por deber del Estado), que cualquier otra persona. Para tanto, se reconoce la necesidad de eventual apoyo en la toma de decisión sobre las situaciones de la vida. Según Dhanda (2008), el modelo social adoptado por la Convención expresa la urgencia de compatibilizarse autonomía y necesidad de apoyo, capacidad y dependencia, dimensiones que no divergen entre sí ni se neutralizan. Prosigue Dhanda:

La búsqueda explícita de apoyo posibilita el reconocimiento de la interdependencia humana, lo cual no es una declaración de incapacidad, sino una admisión honesta de que las personas con discapacidades pueden precisar de apoyo para ejercer sus capacidades. (Dhanda 2008, p. 50)

Al afirmar que la noción de capacidad está determinada por el entorno, porque no es la discapacidad el elemento incapacitante, sino el entorno de la persona (Observatorio de los Derechos Humanos de las Personas con Discapacidad Mental 2014), nos parece que, estratégicamente, el pensamiento que estructura el marco normativo para garantizar los derechos de las personas con discapacidad se puede utilizar perfectamente en el contexto de los niños, niñas y adolescentes brasileños y puede contribuir a salvaguardar la protección calificada y garantista; protección y autonomía. 
El reconocimiento de la capacidad real constatada (Seda 2005), es decir, comprendida a partir de las singularidades del sujeto y no de su edad, no debe dar lugar a la defensa de la falta de responsabilidad del adulto por las demandas de los adolescentes. Más bien, debe implicar "el respeto de los adultos por la singularidad de la experiencia del joven y su derecho a ser responsable en primera instancia de las decisiones que afectan directamente a su vida" (Carvalho et al 2012). Incluso si, para eso, necesite de apoyo. Al igual que el derecho, la capacidad de uno no termina cuando comienza la del otro (niños, adolescentes y adultos), ellas conviven.

Es aquí donde Carvalho y otras (2012, p. 84) son asertivas:

La autonomía sexual debe entenderse como un proceso que ocurre en la vida cotidiana, por lo que debe tejerse a partir de dos líneas principales: protección y libertad. Cabe a los otros, adultos e instituciones que tratan con este público, no se omitir frente a la pluralidad de ser de niños y adolescentes (que son constituidos por sexualidades específicas, en contextos situados), fundamentando relaciones que no se basan únicamente en mecanismos disciplinarios y moralizadores, pero en una práctica implicada y crítica de los conocimientos y experiencias que se refieren al ámbito sexual.

En ese sentido, el dinamismo de las relaciones es una dimensión del ejercicio del derecho al desarrollo de niños y adolescentes. Tanto que, según Buglione (2005), pensar los conflictos sobre los DSDR sería repensar los significados de capacidad y autonomía, que, a su vez, requieren un modelo de racionalidad que presuponga que las personas están cambiando constantemente, en proceso.

\section{Consideraciones finales}

Este artículo buscó evaluar críticamente el debate en Brasil del campo de los derechos sexuales y reproductivos de los adolescentes mediante la presentación de marcos legales y su implementación, en forma de situaciones que afectan directamente a los cuerpos de adolescentes en los sistemas de justicia y de salud. En este balance, demarcamos la presencia de una tensión que se produce entre las prácticas centradas en una perspectiva tutelar y aquellas que se guían por las lógicas autonomistas, estas últimas significativamente presentes en el campo de la salud sexual y reproductiva.

En el contexto brasileño, articular derechos sexuales y reproductivos y salud sexual y reproductiva -aprovechando la mayor madurez de la concepción de esos derechos en el área de la salud y la formulación constitucional del derecho a la salud-puede conducir a avances significativos en la concepción y ampliación del contenido de esos derechos, especialmente para los adolescentes que encuentran mayores obstáculos para su ejercicio (Ventura y Corrêa 2006, Ventura 2009).

De esta manera, nos pareció importante avanzar conceptualmente en el debate sobre el ámbito protección-autonomía, para lo cual la perspectiva de la Convención de Personas con Discapacidad nos brinda una pista importante: la compatibilidad de autonomía y necesidad de apoyo, capacidad y dependencia, dimensiones que no divergen ni se neutralizan entre sí, lo que implica en respeto del adulto en relación con la singularidad de la experiencia del joven y su derecho a ser responsable, en primera instancia, de las decisiones que afectan directamente a su vida.

La promoción de protección con participación y autonomía sólo puede darse por la superación de estereotipos de lo que sea la capacidad para el ejercicio de derechos por 
niños y adolescentes en ciertas edades, tanto en el establecimiento de límites colectivos en comparación con adultos, como de los propios niños y adolescentes entre sí, que deben tener su singularidad individual y social respetada. Se trata de la construcción de un ethos en relación a los niños y adolescentes pautado en la apertura a situaciones y problemáticas que no se dan a priori, sino que se producen en las relaciones y que requieren la sustentación de territorios de convivencia, la experimentación del pensamiento y la intervención contextualizada y colectivizada. Esta disposición pone en juego el ejercicio del actuar común en la dirección de la gestión autónoma y participativa de los conflictos, así como el ejercicio de que nos "desalojemos de la seguridad de valores supuestamente protectores, pero que desconsideran las perspectivas de los propios niños y adolescentes" (Melo 2011, p. 34). Se trata de la revisión del concepto de ciudadanía y de poder, pensados más horizontalmente, incluso sobre los modos en que los niños resisten y desafían las prácticas de adultos.

Sin embargo, incluso dentro de las políticas de salud, sabemos que son grandes los desafíos de garantizar el ejercicio de los mismos derechos sexuales y reproductivos desde una lógica emancipadora que sustente la autonomía, aunque respaldada por el apoyo y la dependencia de otras personas para ayudar en el fortalecimiento de la capacidad relacional.

Por otro lado, en el inicio de 2019, el nuevo gobierno federal del país asume una propuesta que, además de su faceta neoliberal, de imposición de recortes en las inversiones sociales, tiene como agenda el ataque al campo de los derechos humanos. La primera medida en el campo de la infancia y la adolescencia, propuesta por tal gobierno, incide en la prevención del embarazo en la adolescencia (Ley $n^{\circ}$. 13.798), anunciando una disputa también en cuanto a lo que serían las concepciones relativas a la salud sexual y reproductiva en la adolescencia, confirmando así la naturaleza estratégica y táctica de estos derechos como derechos políticos.

\section{Referencias}

Arantes, E.M.M., 2009. Proteção integral à criança e ao adolescente: proteção versus autonomia? Psicologia clínica [en línea], 21(2), 431-450. Disponible en: http://dx.doi.org/10.1590/S0103-56652009000200012 [Con acceso el 10 de enero de 2019].

Arruda, J.S., 2011. "Para ver as meninas": Um estudo sobre as adolescentes em cumprimento de medida socioeducativa de internação na Case/Salvador. Disertación de Maestría. Faculdade de Filosofia e Ciências Humanas. Salvador: Universidade Federal da Bahia.

Baratta, A., 1999. O paradigma de gênero da questão criminal à questão humana. En: C.H. Campos, ed., Criminologia e feminismo. Porto Alegre: Sulina, 19-80.

Bertolini, J., 2016. Garota que ficou presa com 30 homens no Pará leva vida desprotegida. Folha de São Paulo [en línea], 3 de noviembre. Disponible en: http://www1.folha.uol.com.br/cotidiano/2016/11/1828880-garota-que-ficou-presacom-30-homens-no-para-leva-vida-desprotegida.shtml [Con acceso el 8 de abril de 2018]. 
Brito, E.Z.C., 2007. Justiça e gênero: Uma história da Justiça de menores em Brasília (19601990). Editora Universidade de Brasília, Finatec.

Buglione, S., 2005. Sujeito de Direito X Sujeito Sexual. En: R.C.F. Adorno, A.T. Alvarenga y M.P.C. Vasconcelos, eds., 2005. Jovens, trajetórias, masculinidades e direitos. Fapesp, Editora da Universidade de São Paulo, 53-74.

Caetano, C.C., Scisleski, A.C.C., y Galeano, G.B., 2019. El investigador como testigo de la vida de la juventud infame. Athenea digital [en línea], 19(1), e2193. Disponible en: https://doi.org/10.5565/rev/athenea.2193 [Con acceso el 26 de febrero de 2019].

Caldeira, M.T., 2000. Cidade de muros. Crime, segregação e cidadania em São Paulo. São Paulo: Ed. 34, Edusp.

Carvalho, C.S., et al., 2012. Direitos sexuais de crianças e adolescentes: avanços e entraves. Psicologia clínica [en línea], 24(1), 69-88. Disponible en: http://www.scielo.br/scielo.php?script=sci arttext\&pid=S0103-56652012000100006 [Con acceso el 20 de junio de 2019].

Castro, L.R., 2001. Da invisibilidade à ação: crianças e jovens na construção da cultura. En: L.R. Castro, ed., 2001. Crianças e jovens na construção da cultura. Río de Janeiro: NAU / Faperj, 19-46.

Castro, L.R., 2007. A politização (necessária) do campo da infância e da adolescência. Revista Psicologia Política [en línea], 7(14), 1-19. Disponible en: http://pepsic.bvsalud.org/scielo.php?script=sci arttext\&pid=S1519549X2007000200005 [Con acceso el 5 de septiembre de 2019].

Child Rights International Network, 2016. Age is Arbitrary: Setting Minimum Ages [en línea]. Disponible en:

https://archive.crin.org/sites/default/files/discussion paper - minimum ages.pdf [Con acceso el 8 de enero de 2019].

Conselho Nacional de Justiça, 2015. Dos espaços aos direitos: A realidade na ressocialização na aplicação da medida socioeducativa de internação das adolescentes do sexo feminino em conflito com a lei nas cinco regiões do país [en línea]. Brasilia: Conselho Nacional de Justiça. Disponible en: http://www.cnj.jus.br/files/conteudo/destaques/arquivo/2015/06/cb905d37b1c494f 05afcla14ed56d96b.pdf [Con acceso el 17 de abril de 2019].

Convención sobre los derechos de las personas con discapacidad, 2006 [en línea]. Nueva York: Asamblea General de las Naciones Unidas, 13 de diciembre. Disponible en: https://www.ohchr.org/SP/HRBodies/CRPD/Pages/disabilitiesconvention.aspx [Con acceso el 20 de junio de 2019].

Cruz Neto, O., 1996. STF absolve acusado de estuprar menor. Folha de São Paulo [en línea], 16 de mayo. Disponible en: http://www1.folha.uol.com.br/fsp/1996/5/16/cotidiano/38.html [Con acceso el 10 de abril de 2018].

Dhanda, A., 2008. Construindo um novo léxico dos direitos humanos: Convenção sobre os Direitos das Pessoas com Deficiências. SUR - Revista Internacional de Direitos 
Humanos [en línea], 5(8), 42-59. Disponible en: http://dx.doi.org/10.1590/S1806$\underline{64452008000100003}$ [Con acceso el 20 de junio de 2019].

Diniz, D., 2015. Nome de horror. Revista Liberdades [en línea], no 20, pp. 234-244.

Disponible en: https://www.ibccrim.org.br/docs/Lib20 integra.pdf [Con acceso el 17 de abril de 2019].

Diniz, D., 2017. Meninas fora da lei: A medida socioeducativa de internação no Distrito Federal [en línea]. Brasilia: Letras Livres. Disponible en: http://ens.sinase.sdh.gov.br/ens2/images/Biblioteca/Livros e Artigos/AnisMeninas-fora-da-lei-2017-2.pdf [Con acceso el 17 de abril de 2019].

Diniz, D., y Paiva, J., 2014. Mulheres e prisão no Distrito Federal: itinerário carcerário e precariedade da vida. Revista Brasileira de Ciências Criminais, 111, 313-328.

Duarte, J.F., 2016. Para além dos muros: As experiências sociais das adolescentes privadas de liberdade [en línea]. Disertación de Maestría en Servicio Social. Pontifícia Universidade Católica do Rio Grande do Sul, 22 de enero. Disponible en: http://tede2.pucrs.br/tede2/handle/tede/6534 [Con acceso el 17 de abril de 2019].

Fachinetto, R.F., 2008. A "Casa de Bonecas": Um estudo de caso sobre a unidade de atendimento sócio-educativo feminino do RS. Disertación de Maestría. Porto Alegre: Universidade Federal do Rio Grande do Sul.

Fajardo, S.P., 2003. Retórica e realidade dos direitos da criança e do adolescente no Brasil: Uma análise sociojurídica da Lei Federal n. 8069, de 13 de julho de 1990. Tesis de Doctorado en Derechos Humanos y Libertades Fundamentales. Universidad de Zaragoza.

Federação Brasileira das Sociedades de Ginecologia e Obstetrícia, 2008. Saúde da Adolescente: Manual de orientação [en línea]. Brasilia. Disponible en http://www.itarget.com.br/newclients/sggo.com.br/2008/extra/download/SAUDE -DA-ADOLESCENTE [Con acceso el 5 de julio de 2019].

Franco, M.H., Racy, V.L.S., y Simonetti, M.C.M., 2012. Direitos sexuais e reprodutivos de jovens e adolescentes. Revista Brasileira Adolescência e Conflitualidade, 7, 114-130.

Frasseto, F.A., et al., 2012. Gênese e desdobramentos da lei 12594/2012: reflexos na ação socioeducativa. Revista Brasileira Adolescência e Conflitualidade, 6, 19-72.

Freeman, M., 1997. The moral status of children. In: M. Freeman, The Moral Status of Children: Essays on the Rights of the Child. Boston: Martinus Nijhoff, 1-17.

Froemming, C.N., 2016. Da seletividade penal ao percurso punitivo: A precariedade da vida das adolescentes em atendimento socioeducativo. Tesis de Doctorado en Política Social. Universidade de Brasília.

Grillo, N.E., 2018. Força pra subir, coragem na descida: Um estudo sobre as resistências das meninas na Fundação CASA [en línea]. Disertación de Maestría en Psicología Social. Pontifícia Universidade Católica de São Paulo, 26 de abril. Disponible en: https://tede2.pucsp.br/handle/handle/21212 [Con acceso el 17 de abril de 2019].

Jimenez, L., y Frasseto, F.A., 2015. Face da morte: a lei em conflito com o adolescente. Psicologia \& Sociedade [en línea], 27(2), 404-414. Disponible en: http://www.scielo.br/pdf/psoc/v27n2/1807-0310-psoc-27-02-00404.pdf [Con acceso el 18 de julio de 2019]. 
Lourau, R.A., 1993. Análise institucional e práticas de pesquisa. Río de Janeiro: UERJ.

Melo, E.R., 2008. Direito e norma no campo da sexualidade na infância e na adolescência. En: M.A. Ungaretti, ed., Criança e adolescente: Direitos, sexualidades e reprodução. São Paulo: ABMP / Child Hood Brasil, 43-56.

Melo, E.R., 2011. Crianças e adolescentes em situação de rua: Direitos humanos e justiça. São Paulo: Malheiros.

Melo, E.R., 2018. A subjetivação jurídico-política de crianças e adolescentes e (o direito ao) o desenvolvimento: Contribuições críticas do debate filosófico contemporâneo. Relatoría (examen de cualificación de Doctorado). Universidade de São Paulo.

Ministério da Mulher, da Família e dos Direitos Humanos, 2019. Aberta consulta pública sobre o atendimento socioeducativo voltado às adolescentes privadas de liberdade [en línea]. Nota de prensa. 7 de enero. Brasilia: Ministério da Mulher, da Família e dos Direitos Humanos. Disponible en: https://www.mdh.gov.br/todas-asnoticias/2019/janeiro/aberta-consulta-publica-sobre-o-atendimentosocioeducativo-voltado-as-adolescentes-privadas-de-liberdade [Con acceso el 8 de enero de 2019].

Ministério da Saúde, 2010. Diretrizes nacionais para a atenção integral à saúde de adolescentes e jovens na promoção, proteção e recuperação da saúde [en línea]. Brasilia: Ministério da Saúde, Secretaria de Atenção à Saúde, Departamento de Ações Programáticas Estratégicas. Disponible en: http://bvsms.saude.gov.br/bvs/publicacoes/diretrizes nacionais atencao saude a dolescentes jovens promocao saude.pdf [Con acceso el 5 de septiembre de 2019].

Nunes, A., 2016. A juíza que prendeu uma garota por 26 dias na cela dos homens vai receber sem trabalhar nos próximos dois anos. Veja [en línea], 13 de octubre. Disponible en: https://veja.abril.com.br/blog/augusto-nunes/a-juiza-que-prendeuuma-garota-por-26-dias-na-cela-dos-homens-vai-receber-sem-trabalhar-nosproximos-dois-anos/ [Con acceso el 8 de abril de 2018].

O Globo Brasil, 2012. STJ absolve acusado de estuprar garotas de programa de 12 anos. O Globo [en línea], 27 de marzo. Disponible en:

https://oglobo.globo.com/brasil/stj-absolve-acusado-de-estuprar-garotas-deprograma-de-12-anos-4429222 [Con acceso el 10 de abril de 2018].

Observatorio de Derechos Humanos de las Personas con Discapacidad Mental, 2014. Derechos Humanos de las Personas con Discapacidad Mental: Diagnóstico de la Situación en Chile [en línea]. Santiago de Chile. Disponible en: https://www.hogardecristo.cl/rostrosnuevos/wpcontent/files $\mathrm{mf} / 1454518040$ resumenejecutivo1.2.pdf [Con acceso el 18 de julio de 2019].

Oliveira, F., 2004. Um olhar feminista sobre o Cairo+0. En: A.J. Caetano, J.E.D. Alves y S. Corrêa, eds., Dez anos do Cairo: Tendências da fecundidade e direitos reprodutivos no Brasil. Campinas: Associação Brasileira de Estudos Populacionais, 59-69.

Oliveira, M.C., 2011. Direitos sexuais e reprodutivos de adolescentes: conquistas e lacunas assistenciais na política de saúde. Revista de Políticas Públicas [en línea], 
15(2), 225-232. Disponible en: http://dx.doi.org/10.1590/S0104-42302012000100014 [Con acceso el 5 de septiembre de 2019].

Perminio, H.B., et al., 2018. Política Nacional de Atenção Integral a Saúde de Adolescentes Privados de Liberdade: uma análise de sua implementação. Ciência e Saúde Coletiva [en línea], 23(9), 2859-2868. Disponible en: https://doi.org/10.1590/1413-81232018239.13162018 [Con acceso el 8 de enero de 2019].

Pirotta, W.R.B., y Pirotta, K.M.C., 2005. Relações de gênero e poder: os adolescentes e os direitos sexuais e reprodutivos no Estatuto da Criança e do Adolescente. En: R.C.F. Adorno, A.T. Alvarenga y M.P.C. Vasconcelos, eds., Jovens, trajetórias, masculinidades e direitos. Fapesp, Editora da Universidade de São Paulo, 75-90.

Ramos, M.B., 2007. Meninas privadas de liberdade: A construção social da vulnerabilidade penal de gênero. Disertación de Maestría en Servicio Social. Porto Alegre: Pontifícia Universidade Católica do Rio Grande do Sul.

Ribeiro, M.G.C.I., y Busson, S., 2008. Norma e cultura: diversificaçãodas infâncias e adolescências na sociedade brasileira contemporânea de acordo com os direitos sexuais e reprodutivos. En: M.A. Ungaretti, ed., Criança e adolescente: Direitos, sexualidades e reprodução. São Paulo: ABMP / Child Hood Brasil, 61-86.

Rosemberg, F., y Mariano, C.L.S., 2010. A Convenção Internacional sobre os direitos da criança: debates e tensões. Cadernos de Pesquisa [en línea], 40(141), 693-728.

Disponible en: http://www.scielo.br/pdf/cp/v40n141/v40n141a03.pdf [Con acceso el 5 de septiembre de 2019].

Seda, E., 2005. Estatuto da Criança e do Adolescente Comentado para os cidadãos das comunidades urbanas, rurais e indígenas. Río de Janeiro: Ades. Disponible en: http://jusro.com.br/wp-content/uploads/2013/01/edson-seda.pdf [Con acceso el 5 de julio de 2019].

Silva, P.M M.S., y Silva, J.R., 2007. A menina, o encanador e o ministro. Revista PADE [en línea], 2(1/07), 107-119. Disponible en:

https://www.publicacoesacademicas.uniceub.br/pade/article/view/150/139 [Con acceso el 10 de abril de 2018].

Souza, I.S., 2017. Determinantes da institucionalização de crianças e adolescentes em tempos da doutrina da proteção integral [en línea]. Disertación de Maestría. Universidade Nova de Lisboa. Disponible en https://run.unl.pt/bitstream/10362/20739/1/Souza\%20Isadora\%20TM\%202017.pdf [Con acceso el 5 de julio de 2019].

Souza, S.J., 2008. Criança e adolescente: construção histórica e social das concepções de proteção, direitos e participação. En: M.A. Ungaretti, ed., Criança e adolescente: Direitos, sexualidades e reprodução. São Paulo: ABMP / Child Hood Brasil, 87-100.

Ventura, M., 2009. Direitos Reprodutivos no Brasil [en línea]. Brasília: Fundo de População das Nações Unidas. Disponible en: http://www.unfpa.org.br/Arquivos/direitos reprodutivos3.pdf [Con acceso el 5 de septiembre de 2019]. 
Ventura, M., y Corrêa, S., 2006. Adolescência, sexualidade e reprodução: construções culturais, controvérsias normativas, alternativas interpretativas. Cadernos de Saúde Pública [en línea], 22(7), 1505-1509. Disponible en: http://dx.doi.org/10.1590/S0102311X2006000700014 [Con acceso el 5 de septiembre de 2019].

Waiselfisz, J.J., 2012. Mapa da violência 2012. Atualização: Homicídio de mulheres no Brasil [en línea]. Río de Janeiro: Centro Brasileiro de Estudos Latino-Americanos / FLACSO Brasil. Disponible en: https://assets-compromissoeatitudeipg.sfo2.digitaloceanspaces.com/2012/08/MapaViolencia2012atualizacaoagosto_H omicidiosMulheres.pdf [Con acceso el 11 de enero de 2018].

Waiselfisz, J.J., 2013. Mapa da violência 2013: Homicídios e juventude no Brasil [en línea]. Brasília: Secretaria Nacional da Juventude. Disponible en: https://oglobo.globo.com/arquivos/mapa 2013 jovens.pdf [Con acceso el 11 de enero de 2018].

\section{Referencias normativas}

Decreto $n^{\circ}$. 6.286, de 5 de dezembro de 2007. Institui o Programa Saúde na Escola PSE, e dá outras providências [en línea]. Disponible en: http://www.planalto.gov.br/ccivil 03/ Ato2007-2010/2007/Decreto/D6286.htm [Con acceso el 8 de enero de 2019].

Lei no. 12.015, de 7 de agosto de 2009. Altera o Título VI da Parte Especial do DecretoLei oㅡ 2.848, de 7 de dezembro de 1940 - Código Penal, e o art. 1ㅇda Lei no 8.072, de 25 de julho de 1990, que dispõe sobre os crimes hediondos, nos termos do inciso XLIII do art. 5o da Constituição Federal e revoga a Lei no 2.252, de 1o de julho de 1954, que trata de corrupção de menores [en línea]. Disponible en: http://www.planalto.gov.br/ccivil 03/ Ato2007-2010/2009/Lei/L12015.htm [Con acceso el 8 de enero de 2019].

Lei n⿳o. 12.594, de 18 de janeiro de 2012. Institui o Sistema Nacional de Atendimento Socioeducativo. Diário Oficial da União [online], 19 de enero. Disponible en: http://www.planalto.gov.br/ccivil 03/ ato2011-2014/2012/lei/112594.htm [Con acceso el 10 de mayo de 2017].

Lei n⿳o. 13.798, de 3 de janeiro de 2019. Acrescenta art. 8o-A à Lei no ${ }^{\circ} .069$, de 13 de julho de 1990 (Estatuto da Criança e do Adolescente), para instituir a Semana Nacional de Prevenção da Gravidez na Adolescência [en línea]. Disponible en: http://www.planalto.gov.br/ccivil 03/ Ato2019-2022/2019/Lei/L13798.htm [Con acceso el 4 de febrero de 2019].

Lei no. 8.069, de 13 de julho de 1990. Dispõe sobre o Estatuto da Criança e do Adolescente e dá outras providências. Diário Oficial da União [en línea], 16 de julio. Disponible en: http://www.planalto.gov.br/ccivil 03/Leis/L8069.htm [Con acceso el 14 de agosto de 2017].

Portaria Interministerial no $*$ 647, de 11 de novembro de 2008 que estabelece as diretrizes para a implantação e implementação da atenção à saúde de adolescentes em conflito com a lei, em regime de internação e internação provisória, em unidades masculinas e femininas [en línea]. Disponible en: 
http://bvsms.saude.gov.br/bvs/saudelegis/sas/2008/prt0647 1111 2008.html [Con acceso el 8 de enero de 2019]. 